\title{
Review
}

Pharmacology

\section{Therapeutic Options for Hydrating Airway Mucus in Cystic Fibrosis}

\author{
Bernadett E. Tildy ${ }^{a}$ Duncan F. Rogers ${ }^{b}$ \\ ${ }^{a}$ Imperial College London, and ${ }^{b}$ National Heart and Lung Institute, Imperial College London, London, UK
}

\section{Key Words}

Mucus · Lung · Cystic fibrosis · Cystic fibrosis transmembrane conductance regulator gene.

Hypertonic saline · Ivacaftor · Bronchitol · Mannitol ·

Mucus hydration - Moli1901

\section{Abstract}

Background: In cystic fibrosis (CF), genetic mutations in the CF transmembrane conductance regulator (CFTR) gene cause reduced chloride efflux from ciliated airway epithelial cells. This results in a reduction in periciliary liquid $(\mathrm{PCL})$ depth of the airway surface liquid due to associated reduced water efflux. PCL layer dehydration reduces mucociliary clearance (MCC), leading to airway obstruction (reduced airflow and inflammation due to pathogen invasion) with mucus plug formation. Summary: Rehydrating mucus increases MCC. Mucus hydration can be achieved by direct hydration (administering osmotic agents to set up an osmotic gradient), using CFTR modulators to correct dysfunctional CFTR, or it can be achieved pharmacologically (targeting other ion channels on airway epithelial cells). Key Messages: The molecular mechanisms of several therapies are discussed in the context of pre-clinical and clinical trial studies. Currently, only the osmotic agent 7\% hypertonic saline and the CFTR 'potentiator' VX-770 (ivacaftor) are used clinically to hydrate mucus. Emerging therapies include the osmotic agent mannitol (Bronchitol), the intracellular $\mathrm{Ca}^{2+}$-raising agent Moli1901/lancovutide, the CFTR potentiator sildenafil [phosphodiesterase type 5 (PDE5) inhibitor] and the CFTR 'corrector' VX-809 (lumacaftor). Other CFTR correctors (e.g. 'chemical chaperones') are also showing pre-clinical promise.

(c) 2015 S. Karger AG, Basel

\section{Introduction}

Airway mucus secretion is a normal physiological process involved with homeostasis and is a component of the innate immune response in the respiratory tract [1] (table 1). However, mucus hypersecretion, with abnormal mucus consistency, causes airway obstruction by reducing mucociliary clearance (MCC) in respiratory diseases such as cystic fibrosis (CF), chronic obstructive pulmonary disease and asthma [1].

Airway mucus, also termed airway surface liquid (ASL), comprises a gel-like layer above the periciliary liquid (PCL) layer which surrounds the cilia of ciliated airway epithelial cells [2] (fig. 1). Of the three diseases of the respiratory tract mentioned, it is $\mathrm{CF}$ where there is the

\section{KARGER 125}

E-Mail karger@karger.com www.karger.com/pha
(C) 2015 S. Karger AG, Basel

0031-7012/15/0954-0117\$39.50/0
Duncan F. Rogers

National Heart and Lung Institute, Imperial College London Dovehouse Street

London SW3 6LB (UK)

E-Mail duncan.rogers@imperial.ac.uk 
Table 1. Functions of ASL ('mucus')

Provision of a physical barrier to inhaled airborne irritants, particles and micro-organisms as well as aspirated food and liquid

Trapping of irritants, particles, micro-organisms and food

Formation of a transportable 'vehicle' upon which irritants are removed from the airways by mucociliary clearance

Provision of a 'waterproof' layer to limit desiccation (e.g. of the epithelium)

'Humidification' of inspired air

$\mathrm{pH}$ buffering capacity

Neutralisation of inhaled noxious gases

Provision of a selective macromolecular 'sieve'

Provision of a 'store' of immunoglobulins and enzymes (e.g. antibacterial - lysozyme) and provision of an extracellular surface for their activity

most intense interest in identifying targets and drugs to alleviate the mucus problems associated with airway pathophysiology [1].

\section{CF: Genetics and Pathophysiology}

$\mathrm{CF}$ is an autosomal recessive disorder caused by mutations in the $\mathrm{CF}$ transmembrane conductance regulator (CFTR) gene [3]. The frequency of CF occurrence varies worldwide, but is approximately 1 in 2,500 live births. Nearly 2,000 mutations have been identified, although $\sim 70 \%$ of CF patients are homozygous for the F508del mutation [4]. Other CFTR mutations are rare, with just four (G542X, N1303K, G551D and W1282X) having a worldwide prevalence of $\sim 1-3 \%$ each; the remaining proportion of $\mathrm{CF}$ cases are unique to individuals/families (frequency $<0.1 \%$ ) [5]. Mutations have variable effects on disease severity, with some (e.g. N1303K) not being correlated with lung disease severity [6].

The predominant function of CFTR is a cAMP-dependent transmembrane $\mathrm{Cl}^{-}$channel at epithelial surfaces [7]. When intracellular cAMP-dependent protein kinases $\mathrm{A}$ and $\mathrm{C}$ phosphorylate the CFTR regulatory domain (Rdomain), the ATP-binding affinity of the nucleotidebinding domains (NBDs) of the CFTR is increased. When ATP hydrolyses the ATP-binding sites of the NBDs, the two NBDs dimerise and the resulting conformational change opens the channel [8] (fig. 2).

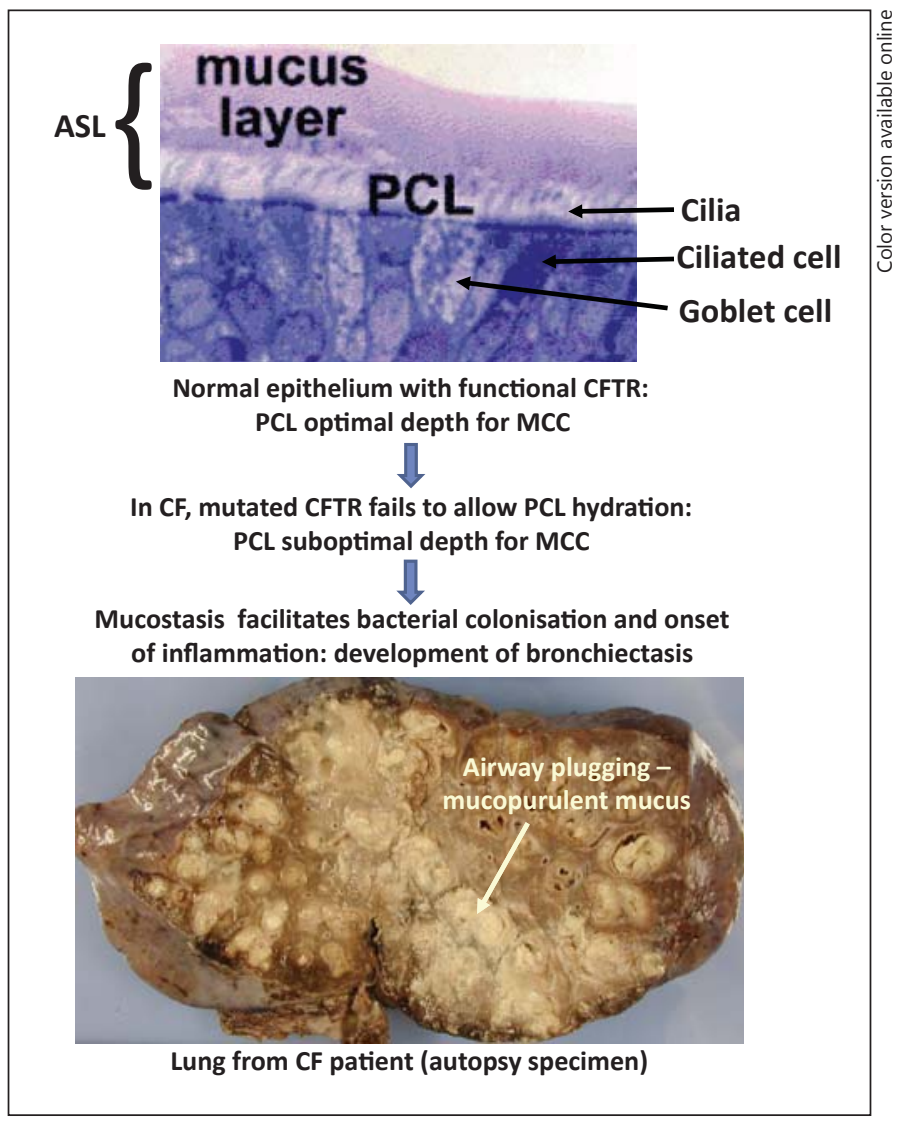

Fig. 1. Relative locations of the gel-like mucus layer and PCL components of ASL. Mutated CFTR leads to dehydrated PCL/ASL, impaired MCC and the pathophysiological sequelae of CF. Methods to achieve mucus hydration are targeted at the ion channels (of ciliated airway epithelial cells?), which are adjacent to the mucussecreting goblet cells in the respiratory tract.

In $\mathrm{CF}$, there is a reduction in PCL depth linked to reduced water efflux due to reduced $\mathrm{Cl}^{-}$efflux caused by malfunctioning CFTR [9]. PCL layer dehydration reduces ciliary beat frequency, which slows the MCC rate [10], allowing mucus plug formation, resulting in the following symptoms of the disease: reduced airflow and inflammation due to pathogen invasion [11].

One therapeutic approach against mucus accumulation is mucus hydration, because this increases MCC. Mucus hydration can be achieved by three main methods:

- Direct hydration

- CFTR modulators

- Pharmacologically - using drugs which target other ion channels on airway epithelial cells

An extensive portfolio of drug compounds is being developed to aid the above approaches to airway mucus hydration (table 2; fig. 3) and is described in detail below. 


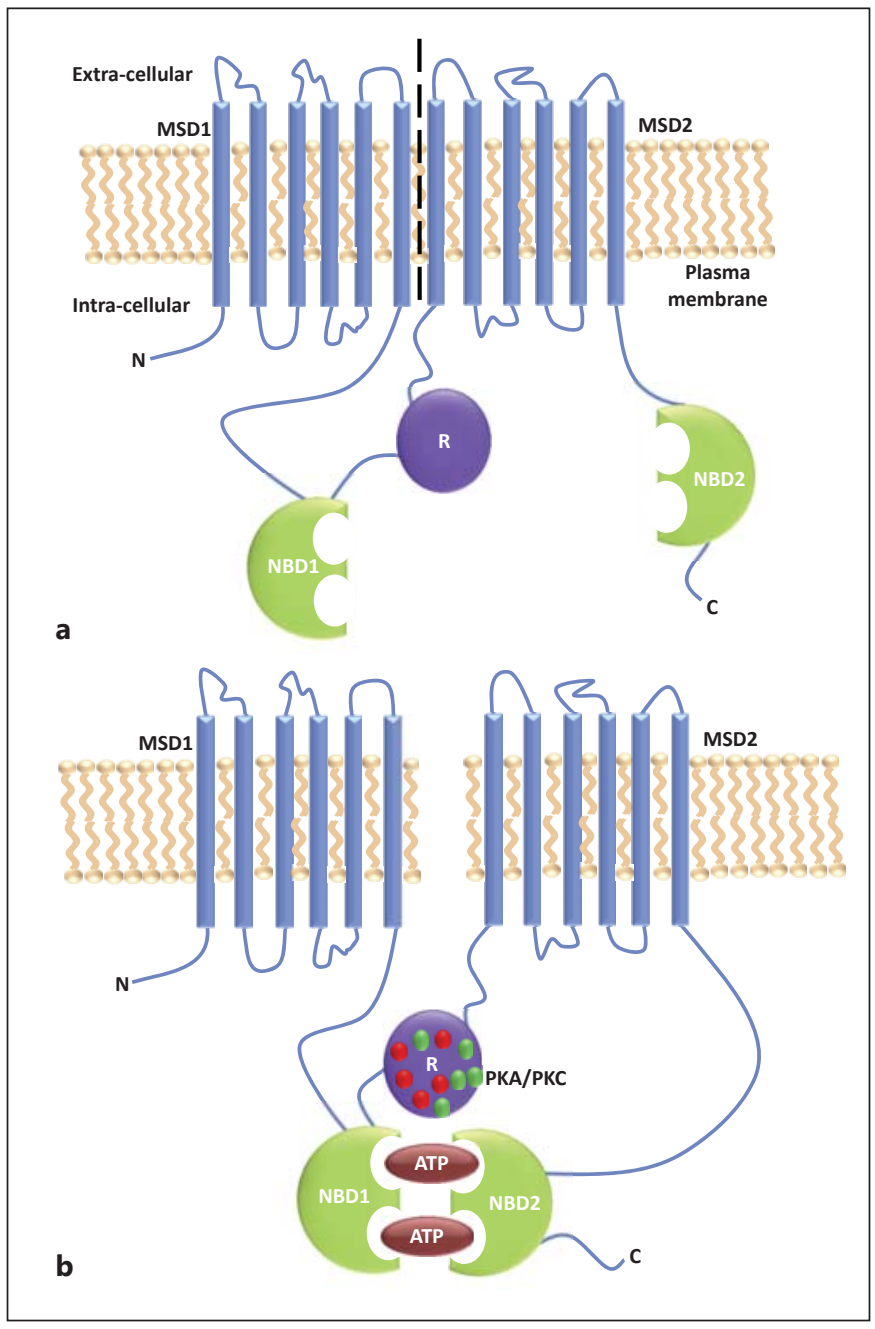

Fig. 2. CFTR. It is an ATP-binding cassette transporter, consisting of two main MSDs (either side of the dashed line), two NBDs, and a regulatory domain (R-domain). a In the 'resting state', the NBDs are disassociated from each other, do not interact with the R-domain and the channel is 'closed' (reduced open probability). b Upon stimulation by intracellular cAMP-dependent protein kinases $\mathrm{A}$ and $\mathrm{C}$ (PKA/PKC) the R-domain phosphorylates, thereby increasing ATP-binding affinity. ATP binds to the NBDs, causing dimerisation of NBD1 and NBD2. This results in a conformational change, leading to an opening of the ion channel (increased open probability).

\section{Direct Hydration}

Administering aerosolised hypertonic saline (HS) or dry powder mannitol (Bronchitol) into the airways sets up an osmotic gradient which draws water through epithelial cells' aquaporins, rehydrating the PCL $[12,13]$ (fig. 4).

Therapeutic Options for Hydrating Airway Mucus in CF
Table 2. Drug compounds intended to aid hydration of ASL (see text for details): classification for hydrating airway mucus in CF

\section{Osmolytics}

HS

Mannitol (Bronchitol)

O Pharmacological compounds

Amiloride

Amiloride analogues: 552-02, GS-9411

Camostat

'Compound 12g' (a-branched quaternary amine)

Denufosol

INO-4995

Moli1901/lancovutide (duramycin)

Small peptide RFSHRIPLLIF

\section{CFTR modulators}

3-Isobutyl-1-methylxanthine (IBMX)

Betaine

Bortezomib/Velcade/PS-341

Corrector 'Corr-4a' (bisaminomethylbithiazole)

Curcumin

G418 (Geneticin)

Genistein

Gentamicin

Glycerol

Matrine

Miglustat

Myoinosotil

PCT124 (ataluren)

Sildenafil

Sildenafil analogues: ardenafil, tadalafil, KM11060

Sodium 4-phenylbutyrate (Buphenyl)

Suberoylanilide hydroxamic acid (SAHA)

Thapsigargin

Tobramycin

Trimethylamine N-oxide

VRT-325

VRT-532

VX-770 (ivacaftor)

VX-809 (lumacaftor)

\subsection{Hypertonic Saline}

HS is used for experimental sputum induction in respiratory diseases such as chronic obstructive pulmonary disease and asthma, but can also be used therapeutically, usually as a $7 \%$ solution [14].

Therapeutic efficacy can be measured by the MCC rate, for example as the amount of sulphur colloid in expectorated sputum [15]. However, using the sulphur colloid content as a marker for clearance does not differentiate between mucus composition (e.g. hydration) and ciliary beating, or both in combination [16]. Consequently, 


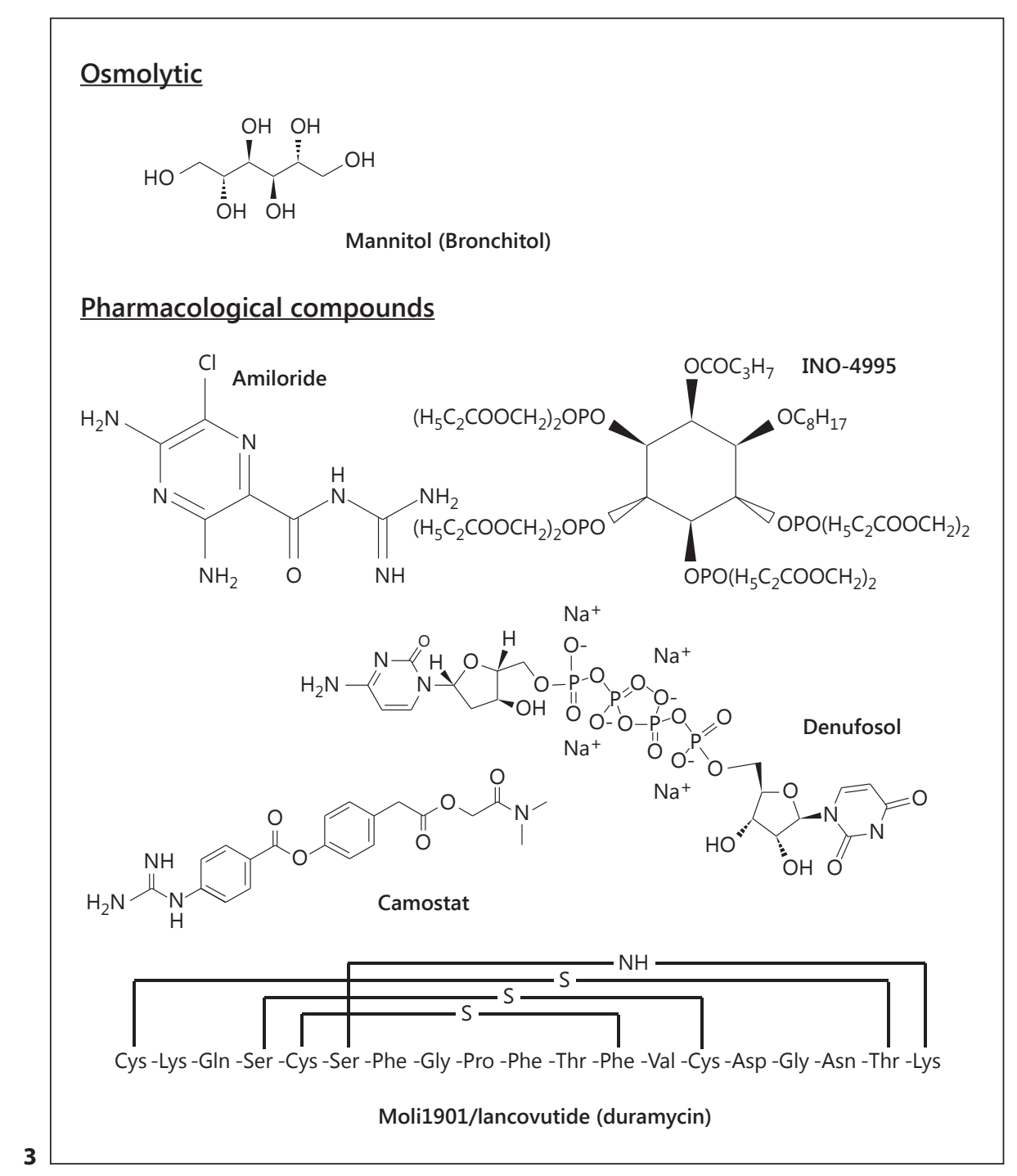

(For legend see page 122.)

whether or not increased mucus clearance by HS is due to hydration is unclear. Inhalation of HS for $90 \mathrm{~min}$ improved MCC by $12 \%$, although concomitant amiloride $\left(\mathrm{Na}^{+}\right.$channel blocker) did not significantly further increase clearance [14] (due to a possible negative feedback effect on epithelial $\mathrm{Na}^{+}$channel $(\mathrm{ENaC})$ triggered by increased intracellular $\mathrm{Na}^{+}$concentration as a result of water efflux [17]). The clinical significance of a $12 \%$ increase in MCC was not defined. HS changes the rheology of expectorated mucus in vitro (reducing viscoelasticity by disrupting ionic bonds) [18], induces inflammatory mediator release such as prostaglandin $\mathrm{E}_{2}$ [19] (which increases ciliary beat frequency) [20] and induces coughing [14], which increases total MCC [17].
Nevertheless, although the exact mechanism of action of HS is unknown, HS is an effective treatment. In clinical trials, the effect of HS was measured focusing on lung function, rate of pulmonary exacerbations and mucus clearance. HS significantly increased forced vital capacity compared to baseline values, and HS on its own produced a sustained increase $(\geq 8 \mathrm{~h})$ in mucus clearance [21]. Accompanying in vitro experiments (cultures of patients' bronchial epithelium) demonstrated changed ASL volume after HS application [21]. HS has long-term positive effects. The absolute lung function increase was significantly different between the control and the HS group, and the ' 48 -week exacerbation-free survival' rate was $14 \%$ significantly higher in the HS group in comparison to the control group [22]. Recently, HS has shown short-term 


\section{CF modulators}

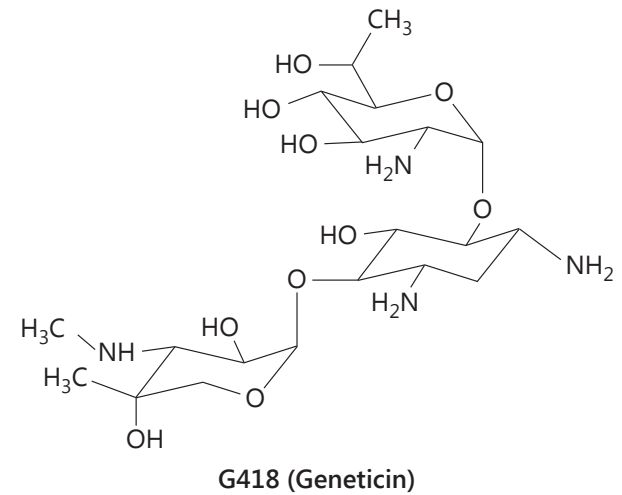

$\underbrace{\mathrm{O}-\mathrm{N}}_{\mathrm{C}}{ }_{\mathrm{OH}}^{\mathrm{O}}$

PCT124 (ataluren)

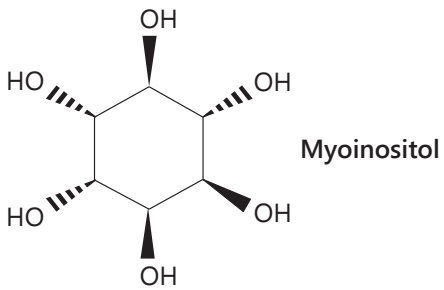

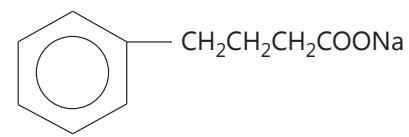

Sodium 4-phenylbutyrate (Buphenyl)

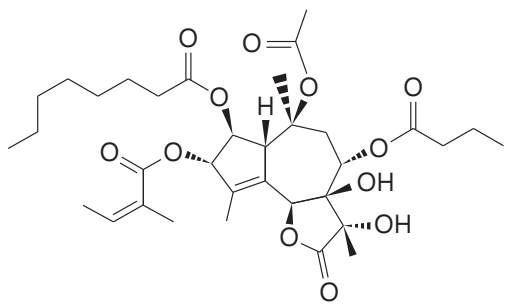

Thapsigargin

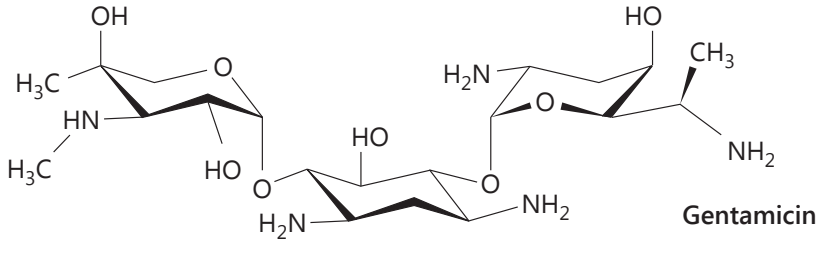<smiles>NC[C@H]1O[C@@H](O[C@@H]2[C@@H](N)C[C@@H](N)[C@H](O[C@@H]3OC(CO)[C@@H](O)[C@H](N)[C@H]3O)[C@H]2O)[C@H](N)C[C@@H]1O</smiles><smiles>OCC(O)CO</smiles>

Glycerol

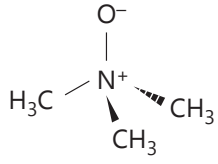

Trimethylamine $\mathrm{N}$-oxide
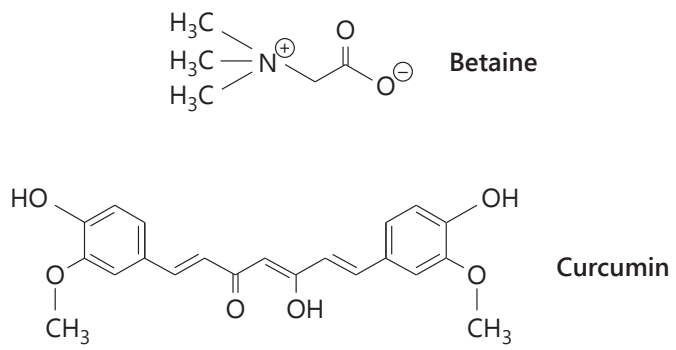<smiles>O=c1c(-c2ccc(O)cc2)coc2cc(O)cc(O)c12</smiles>

(For legend see next page.) 
(CF modulators continued)<smiles>O=C(CCCCCCC(=O)Nc1ccccc1)NO</smiles>

Suberoylanilide hydroxamic acid (SAHA)<smiles>COc1ccc(S(=O)(=O)N2CCN(C(C)c3nc(OC4CCCCC4)c4ccccc4n3)CC2)cc1</smiles><smiles>COc1ccc(Cl)cc1Nc1nc(-c2sc(NC(=O)c3ccccc3)nc2C)cs1</smiles>

Corrector Corr-4a

(bisaminomethylbithiazole)<smiles>CCOC(=O)c1ccc(-c2nc(NC(=O)C3(c4ccc5c(c4)OC(F)(F)O5)CC3)ccc2C)cc1C(=O)O</smiles><smiles>CCCc1nn(C)c2c(=O)nc(-c3cc(S(=O)(=O)N4CCN(C)CC4)ccc3OCC)[nH]c12</smiles>

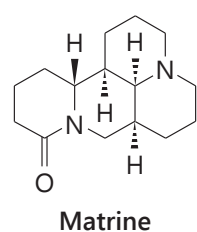<smiles>Cc1ccc(O)c(-c2cc(-c3ccccc3)[nH]n2)c1</smiles>

VRT-532<smiles>CC(C)Cn1c(=O)n(C)c(=O)c2[nH]cnc21</smiles>

3-isobutyl-1-methylxanthine (IBMX)<smiles>CC(C)(C)c1cc(C(C)(C)C)c(NC(=O)c2c[nH]c3ccccc3c2=O)cc1O</smiles>

VX-770 (ivacaftor)<smiles>CCCCN1CC(O)C(O)C(O)C1O</smiles>

Fig. 3. Chemical structures of drug compounds intended to aid hydration of ASL (see text for details).
In summary, HS is relatively inexpensive and well-tol-

efficacy and a lack of adverse effects in infants [23]. An ISIS trial with $321<6$-year-old participants found no significant difference in the rate of pulmonary exacerbations during the 48-week treatment period between HS and isotonic saline groups [24].

When adjusted for height, the 'lung clearance index' as an endpoint showed a significant difference between HS and isotonic saline groups in children aged $<6$ years, albeit with a small sample size $(\mathrm{n}=25)$, after 48 weeks' treatment [25]. erated by adults and infants. However, although there is a dose-dependent relationship between the HS concentration and MCC, most efficacious with 7\% HS, clinical trials show mixed results for HS improving pulmonary function and reducing exacerbation rates [12]. However, there may be an issue with the endpoints against which the efficacy of CF drugs is currently measured [26], because trial results do not translate into clinical outcomes. This issue is worsened by problems of an attempted com- 


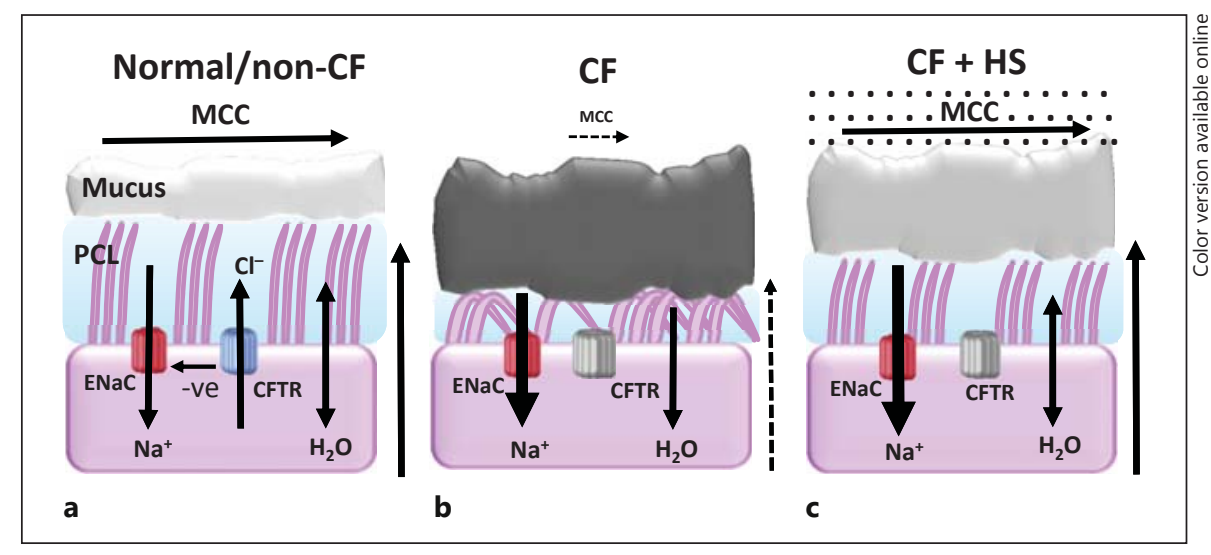

Fig. 4. Effect of HS on hydration of ASL in CF. a In non-CF people, the ASL comprises a PCL layer, in which cilia beat, and an upper mucus layer (which contributes to MCC). CFTR acts as a $\mathrm{Cl}^{-}$channel, permitting $\mathrm{Cl}^{-}$efflux into the airway lumen, with some concomitant $\mathrm{Na}^{+}$absorption via $\mathrm{ENaC}$, thereby establishing an osmotic gradient to drive water efflux into the PCL. b In CF, mu-

parison of CF in infants with CF in adults, where baseline pulmonary function values for very young CF children reflect non-CF values. These endpoints make it difficult to find treatments with best efficacy when administered before CF symptoms are present.

\subsection{Mannitol}

Mannitol is a non-ionic osmotic agent [27]. Inhaled dry mannitol causes mucus hydration by the same mechanism as HS: increasing the osmotic gradient causing water efflux into the lung lumen [28]. The disadvantage of mannitol powder over HS is its relatively large size, so deposition at the intended site, the small airways and the lung periphery [29], is hard to achieve [30]. Similar to HS, mannitol has rheologic effects on mucus; disruption of hydrogen bonds in the mucus reduces viscoelasticity, which increases mucus clearance, and induces cough [31].

Phase 3 studies (in $\geq 6$-year-old CF children) show improved $\mathrm{FEV}_{1}$ and $\sim 35 \%$ reduction in pulmonary exacerbation occurrence [32] and improved lung function [33] after 26 weeks. It should be noted that the control group for these studies received $50 \mathrm{mg}$ mannitol (a dose determined as subtherapeutic in a previous dose-escalation study [34]). However, the 2012 study $(\mathrm{n}=3,138)$ [33] questioned this 50-mg dose, where, although there was $\sim 8 \%$ improvement in $\mathrm{FEV}_{1}$ from baseline in the mannitol

Therapeutic Options for Hydrating

Airway Mucus in CF tated CFTR results in reduced $\mathrm{Cl}^{-}$efflux and, thereby, reduced water secretion. Continued $\mathrm{Na}^{+}$absorption leads to water absorption with associated dehydration of the PCL and defective MCC. c In CF patients, inhaled 7\% HS sets up an osmotic gradient, causing water efflux into the PCL, resulting in ASL rehydration and restored MCC.

group, statistically significant results were not obtained between the 400-mg mannitol and the control group, suggesting that the 50-mg dose may have had some efficacy. Another reason for statistically insignificant results may be that only one data point was collected for baseline $\mathrm{FEV}_{1}$.

In summary, mannitol's easier administration via inhaler (compared to HS nebuliser), similar adverse event rates, more consistent clinical efficacy and longer epithelial retention time may make mannitol the leading treatment in the future. Mannitol may cause bronchoconstriction in patients with hyperresponsive airways, but this is not proven [32]. Although a crossover trial in 6- to 17 -year-olds [35] is currently underway, additional studies are needed to assess mannitol in patients $<6$ years old as well as its inflammation-inducing effects.

\section{CFTR Modulators}

Another way to increase mucus hydration in $\mathrm{CF}$ is to correct dysfunctional CFTR.

\subsection{Mutation Classes}

Different CFTR mutations can cause problems with synthesis, gating, conductance or stability of the channel (fig. 5). 


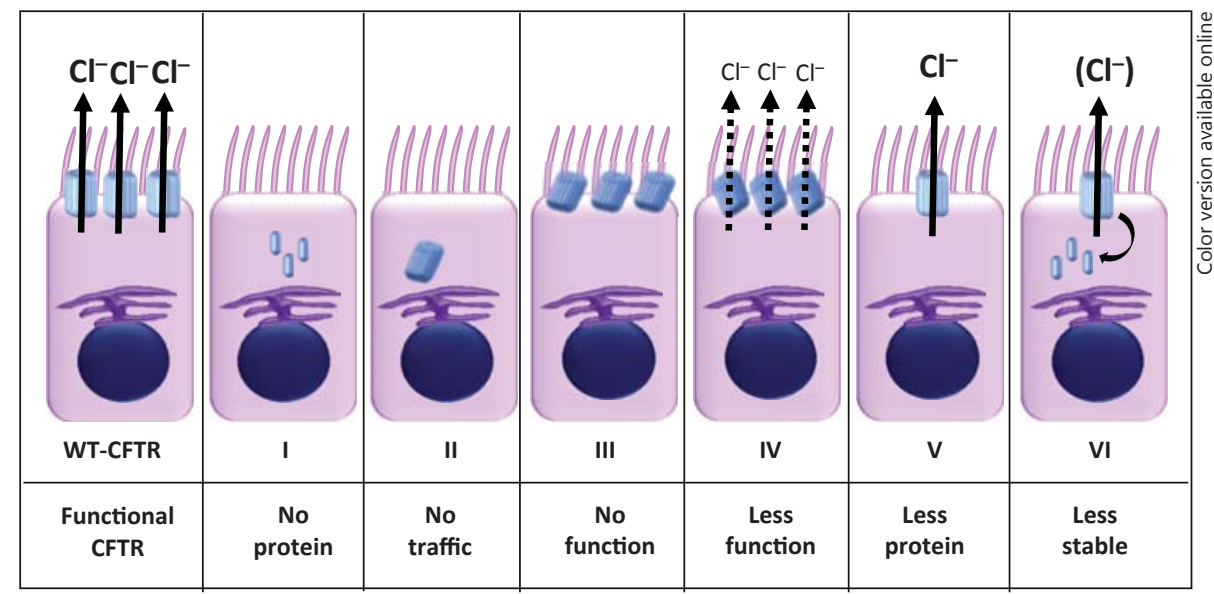

Fig. 5. Summary of the effects on $\mathrm{Cl}^{-}$efflux of the different CFTR mutation classes. WT-CFTR are abundant at the apical surface and permit effective $\mathrm{Cl}^{-}$efflux into the airway lumen. Class I mutations produce truncated CFTR which are degraded before reaching the apical surface. Class II mutations produce misfolded CFTR which are degraded before reaching the apical surface. Class III muta-

\subsubsection{Class I: Reduced Synthesis of CFTR}

These mutations synthesise unstable or truncated CFTRs due to prematurely coding a termination codon into the amino acid sequence. The most common class I mutation is G542X [6] and W1282X in the Ashkenazi Jewish population [36]. If a splicing error occurs instead of a nonsense or a frameshift mutation, some functional CFTRs are synthesised, but total CFTR expression is suboptimal.

\subsubsection{Class II: Defective Processing of CFTR}

The most common mutation (F508del) results in misfolded CFTR synthesis due to deletion of the phenylalanine codon at the 508th amino acid position [4]. Usually, dysfunctional CFTR is degraded before localisation to the apical membrane, but when F508del-CFTR is 'rescued' (trafficked and inserted into the membrane) its gating is defective, classifying it simultaneously as a class III mutation [37].

\subsubsection{Class III: Defective Gating of CFTR}

Amino acid codons are substituted for other amino acids. While transcription and processing events are successful, these channels have defective regulation of ion transfer upon insertion into the membrane (e.g. G551D, glycine-to-aspartate missense mutation) [5].

Class III mutations confer a conformational change to the NBD, negatively affecting ATP-binding capacity, failing to be stimulated by ATP [38]. tions produce CFTR with defective activation (do not permit $\mathrm{Cl}^{-}$ efflux). Class IV mutations produce CFTR with low ion channel conductance (suboptimal $\mathrm{Cl}^{-}$efflux). Class $\mathrm{V}$ mutations produce suboptimal amounts of functional CFTR. Class VI mutations produce unstable CFTR which are quickly degraded.

\subsubsection{Class IV: Reduced $\mathrm{Cl}^{-}$Conductance of CFTR}

CFTR is successfully inserted into the cell membrane but the channel's $\mathrm{Cl}^{-}$conductance is reduced by decreased open state frequency, linked to reduced phosphorylation capacity of cAMP-dependent protein kinases, due to membrane-spanning domain (MSD) mutations [4].

\subsubsection{Class V: Reduced CFTR Synthesis}

Defective CFTR transcription forms both correctly and incorrectly spliced mRNA, resulting in suboptimal amounts of functional CFTRs [5].

\subsubsection{Class VI: Decreased Stability of CFTR at the Apical Membrane}

CFTRs which are functional but have a high turnover at the cell surface are produced; they are degraded 5-6 times faster than normal due to deletion of the C-terminal tail which stabilises folded CFTR [39].

\subsection{Therapy}

Correction of the underlying defect of CFTR mutations by gene replacement therapy is progressing slowly and has significant efficacy and safety problems [40]. Instead, mutation-class-specific drugs aim to correct the molecular mechanism of CFTR dysfunction to regain CFTR function [40]. 


\subsubsection{Class I}

Drugs which correct class I CFTR mutations are termed 'premature stop codon suppressors' or 'readthrough agents' [41].

Aminoglycoside antibiotics disrupt translation by binding to rRNA, thereby inhibiting premature termination by inserting a different amino acid into the sequence [40]. G418 (Geneticin) increased expression of full-length CFTR to 25\% of wild-type CFTR (WT-CFTR) levels in vitro in cells containing R553X-mutated CFTR [42]. Treatment with gentamicin or tobramycin (separately) in vivo in intestinal tissues of mice caused full-length hCFTR localisation to the apical surface [43]. However, longterm use of aminoglycoside antibiotics can cause nephroand ototoxicity [40], and gentamicin and tobramycin are risk factors for acute renal failure in patients with renal/ hydration problems [44].

PCT124 (ataluren) allows 'read-through' of stop codons, allowing transcription to continue, with synthesis of full-length CFTR [45]. Nasal potential difference (NPD) was the biomarker of $\mathrm{Cl}^{-}$transport and drug activity/efficacy. PCT124 induced a $\geq 5 \mathrm{mV}$ change in NPD in children [46] and adults [47] with few/mild adverse effects. PCT124 is undergoing a phase 3 extension study to observe long-term effects [48].

\subsubsection{Class II}

Due to the close interaction between CFTR channel gating and cellular processing, and uncertainties of drug mechanisms, the distinction between CFTR correctors (targeted at cellular processing and trafficking defects [49]) and CFTR potentiators (which correct $\mathrm{Cl}^{-}$channel activity in mutant CFTRs at the cell surface [49]) is ambiguous [50].

\subsubsection{CFTR Correctors}

CFTR synthesis, co-translational folding and interaction with chaperone proteins occur in the endoplasmic reticulum (ER). If CFTR folding time is increased and CFTR is retained in the ER, molecular chaperones transport improperly folded CFTRs to the cytoplasm, where the 26S proteasome degrades them. This process is termed ER-associated degradation. WT-CFTR is transported from the ER to the Golgi where it undergoes N-glycosylation before transportation to the apical membrane [51, 52].

The mechanism underlying the primary therapeutic method against F508del was to reduce CFTR retention in the ER. In vitro, low temperature [53], glycerol [54] and trimethylamine $\mathrm{N}$-oxide [55] correct the processing defect of F508del-CFTR but had cytotoxic effects.
Organic solutes (myoinositol alone/with taurine and betaine) stabilised and promoted glycosylation of F508del-CFTR by increasing hydration of the peptide in IB3 (bronchial) and NIH 3T3 (fibroblast) cells [56]. However, merely releasing F508del-CFTR from the ER was not sufficient to treat CF; protein generation and maintenance by interaction with chaperone proteins are important. CF may be due to incorrect recognition of F508delCFTR by the 'protein homeostasis network' [57]. However, mutated CFTR interaction with certain chaperone proteins (expressed during cell stress response [58]) promotes degradation [44].

The following chaperone proteins have been investigated:

- Hsc70, which associates more strongly with F508delCFTR than with WT-CFTR and promotes degradation [59].

- Hsp70, which enhances F508del-CFTR maturation [60].

- Hsp90, which provides ATPase activity for the proteasome [61], integral to its function, thereby contributing to mutated CFTR degradation.

Chemical and pharmacological chaperones have been investigated. Chemical chaperones are defined as nonspecific small molecules which stabilise cellular proteins by improving the rate or fidelity of protein folding, by acting on chaperone proteins or the proteasome rather than directly on CFTR [62]. Pharmacological chaperones act directly on mutated CFTR.

4.2.2.1.1 Chemical Chaperones. Sodium 4-phenylbutyrate (Buphenyl) with genistein were used in a phase $1 / 2$ clinical trial in 2001 [63]. A similar study in heterozygous F508del patients was conducted in 2007 [64] but was terminated in 2008; the data were not analyzed due to the identification of more clinically efficacious compounds. This may seem reasonable, because Buphenyl only showed statistically significant improvement in NPD (e.g. sweat $\mathrm{Cl}^{-}$concentration was not significantly reduced) in its pilot study [65], although it seemed promising, since in vitro it trafficked mutated CFTR to the apical membrane [66] and downregulated Hsc70 [67].

The sarco-/ER calcium (SERCA) pump inhibitors curcumin and thapsigargin interfere with chaperone proteins by decreasing the $\mathrm{ER} \mathrm{Ca}^{2+}$ concentration, allowing F508del-CFTR release from the ER and restoring CFTR's function $[68,69]$. Conflicting results [70-73] suggest that curcumin does enhance CFTR expression but by downregulating another ER chaperone protein, calreticulin [74]. 
Bortezomib/Velcade/PS-341 is used clinically to treat multiple myeloma by increasing the expression of certain stress response proteins by inhibiting specific proteasomal subunits [75]. Bortezomib increases intracellular Hsp70 [76], thereby rescuing F508del-CFTR from ER-associated degradation [77].

Miglustat inhibits deglucosylation of F508del-CFTR in the ER by inhibiting $\alpha$-1,2-glucosidase in vitro in human nasal, tracheal and pancreatic cells, thereby inhibiting F508del-CFTR interaction with calnexin (another ER-located chaperone protein), preventing CFTR's transport into the cytoplasm and subsequent degradation [78]. Miglustat increased $\mathrm{Cl}^{-}$efflux and reduced $\mathrm{Na}^{+}$influx when administered to mice either intratracheally or orally [79]. However, using RNAi [80] or knock-out mice [81], inhibiting F508del-CFTR-calnexin interaction does not prevent degradation of mutated CFTR. Despite these conflicting pre-clinical data, a phase 2 clinical trial of miglustat [82] $(\mathrm{n}=11)$ went ahead, but produced no significantly different NPD results [83].

Ruling the drug as inefficacious was disputed, suggesting that NPD is not the best measure of drug efficacy, and measurements were prone to error [84]. Ultimately, it was agreed that the effect size was correctly determined (accounting for the small sample size) and the results could not be classed as statistically significant [85].

In vitro in human bronchial cells, inhibiting histone deacetylase 7 (HDAC7) using suberoylanilide hydroxamic acid (SAHA) restores F508del-CFTR function by increasing CFTR expression (due to altering histone acetylation states) and producing a protective and corrective post-translational environment (by modulating protein activity, e.g. downregulating Hsp90) [86].

In vitro in HEK293 cells, downregulating a significant co-chaperone of Hsp90, Aha1, decreases F508del-CFTR degradation [87]. Matrine decreases Hsc70 levels in human alveolar epithelial cells in vitro, promoting F508delCFTR binding to chaperone, BAG3, which promotes translocation to the membrane [88].

4.2.2.1.2 Pharmacological Chaperones. High-throughput screening yielded compounds VRT-325 and VRT532 [89]. VRT-325 binding to CFTR is not specific to F508del-CFTR. VRT-325 binds to F508del-CFTR allosterically, indirectly affecting the NBD [90].

Corrector 'Corr-4a' (bisaminomethylbithiazole) has binding specificity for F508del-CFTR over other mutants and increased folding efficiency (by correcting NDB2 misassembly [91] or interacting with transmembrane domains [92]), preventing degradation by the proteasome via reducing ubiquitination susceptibility, re- sulting in $8 \%$ normal CFTR activity (deemed clinically significant to reduce pathology) [93]. Corr-4a also increases F508del-CFTR residence time at the apical membrane [93].

VX-809 (lumacaftor) binds to mutated CFTR's MSD1, inducing a protein-stabilising conformational change, protecting it from degradation [94]. VX-809's specificity depends on the MSD structure but was shown to rescue CFTR in F508del and other mutations [94]. VX-809 produced a significant change in NPD in a phase 2 clinical trial [95] and is investigated with concomitant VX-770 (CFTR potentiator) and other CF drugs which prevent infection [96].

\subsubsection{CFTR Potentiators}

CFTR potentiators are effective for (class III/IV) mutations where the CFTR has been trafficked to the apical membrane but has a defective ion channel function.

VRT-532 corrects the gating defect of several CFTR mutants, with the highest affinity for F508del-CFTR [89]. It increases ATP-binding affinity of mutated CFTR after protein kinase A activation [97]. VRT-532 corrects G551D-CFTR by increasing ATP binding and hydrolysis, with no effect on WT-CFTR where ATPase activity is already maximal [98].

VX-770 (ivacaftor) has efficacy in both WT-CFTR and mutated CFTR [99], including G511D-CFTR [100]. Although its binding site is unknown, VX-770 mediates channel opening ATP-independently, being able to potentiate gating in G511D mutants, where the ATP-binding site is mutated [100]. Current clinical trials for VX770 include non-G551D mutations [101] and VX-770 in combination with other CF drugs against infection [102] and also with the CFTR corrector VX-809, which improves $\mathrm{FEV}_{1}$ in patients homozygous for F508del-CFTR [103].

The CFTR corrector Buphenyl has been investigated in conjunction with genistein because genistein alone was shown to be a CFTR potentiator [104]. Genistein acts at the NBD, showing 5-fold higher affinity for F508delCFTR than G551D-CFTR [89], increasing ATP binding capacity and so increasing channel open probability [105]. Capsaicin (pungent essence of hot chillies) was shown to have a similar mechanism [106]. Genistein in conjunction with curcumin demonstrated a significant synergistic effect [107]. It also increases ciliary beat frequency [108].

Increasing intracellular cAMP activates CFTR. The phosphodiesterase (PDE) inhibitor 3-isobutyl-1-methylxanthine (IBMX), in conjunction with adenylate cy- 
clase activators [109], produces significant $\mathrm{Cl}^{-}$efflux, albeit at high concentrations and lowered temperature $[110,111]$.

The inhaled PDE5 inhibitor, sildefanil, inhibits cGMP breakdown in vivo in mice [112]. The relevance of cGMP to cAMP was addressed: there is 'crosstalk' between signalling pathways, with increased cGMP inhibiting PDE3 (PDE3 degrades cAMP) [113], suggesting sildefanil increases intracellular cAMP. Sildefanil's potent analogue, KM11060, is effective, but its safety in vivo is unknown [114]. Sildenafil, vardenafil and tadalafil each corrected $\mathrm{Cl}^{-}$conductance in mice orally [115] and when inhaled [112]. Sildenafil had both exocytotic effects on F508delCFTR and ion channel potentiating function, making it both a CFTR corrector and potentiator. However, sildenafil's efficacy is only achieved at high doses [116], but a current phase 2 clinical trial [117], following a phase $1 / 2$ safety trial in 2008 [118], suggests a potentially positive clinical future.

\section{Pharmacological Approaches}

Mucus hydration can be achieved pharmacologically, by targeting either the apical $\mathrm{ENaC}$, the $\mathrm{P}_{2} \mathrm{Y}_{2}$ receptor or the $\mathrm{Ca}^{2+}$-activated $\mathrm{Cl}^{-}$channel (CaCC) (fig. 6).

\subsection{ENaC Inhibitors}

Although the existence of dysfunctional CFTR-mediated hyperabsorption via $\mathrm{ENaC}$ is disputed [119-121], $\mathrm{Na}^{+}$absorption via ENaC controls fluid absorption [122]; therefore, $\mathrm{ENaC}$ activity contributes to CF pathophysiology by reducing PCL depth. Mucus hydration can be achieved using direct and indirect $\mathrm{ENaC}$ inhibitors [123].

\subsubsection{Direct ENaC Inhibitors}

These compounds block open $\mathrm{ENaC}$ directly.

\subsubsection{Amiloride and Amiloride Derivatives}

Amiloride and early amiloride derivatives (phenamil and benzamil) had limited therapeutic usefulness due to rapid absorption/clearance from the lungs [124]. A thirdgeneration amiloride derivative, 552-02, which in vitro in human bronchial cells was 60 -fold more potent and 2 times less reversible than amiloride, showed a significant positive synergistic effect with HS (unlike amiloride-HS treatment, see section on Hypertonic Saline above) and in vivo in sheep increased MCC for $>5$ h [125]. Since a 2006

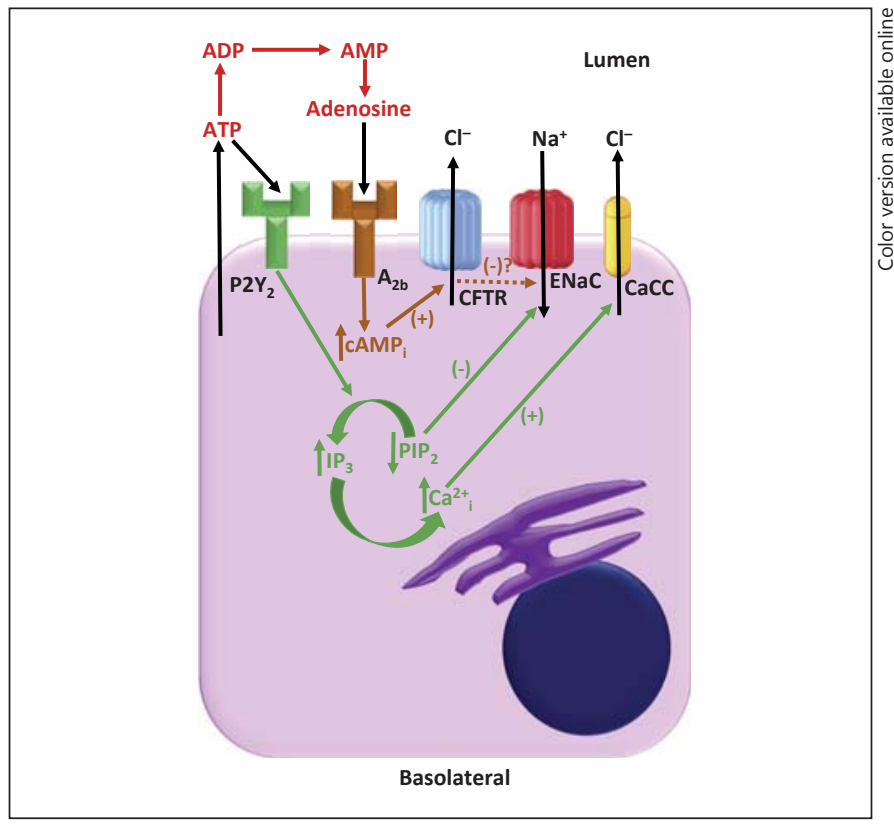

Fig. 6. Summary of pharmacological approaches to hydrating ASL in CF. As well as CFTR modulation, pharmacological approaches targeting the $\mathrm{P}_{2} \mathrm{Y}_{2}$ receptor, the $\mathrm{ENaC}$ and the CaCC are being examined in attempts to achieve mucus hydration in CF. ATP activates $\mathrm{P}_{2} \mathrm{Y}_{2}$ purinoceptors, causing $\mathrm{PIP}_{2}$ hydrolysis to $\mathrm{IP}_{3}$ by phospholipase $\mathrm{C}$, and $\mathrm{Ca}^{2+}$ release from intracellular stores, increasing intracellular $\mathrm{Ca}^{2+}$ concentration. ATP degradation to adenosine (via ADP and AMP) in the lumen results in the activation of adenosine $\mathrm{A}_{2 \mathrm{~b}}$ receptors, leading to the increase of intracellular cAMP concentration, which activates WT-CFTR. $\mathrm{Na}^{+}$absorption via $\mathrm{ENaC}$ contributes greatly to fluid absorption, resulting in PCL depth reduction in the lumen. Direct and indirect $\mathrm{ENaC}$ inhibitors can be used to downregulate ENaC activity. Since $\mathrm{P} 2 \mathrm{Y}_{2}$ purinoceptor activation results in the decrease of intracellular $\mathrm{PIP}_{2}, \mathrm{ENaC}$ activity can be decreased using $\mathrm{P}_{2} \mathrm{Y}_{2}$ purinoceptor agonists. The activation of $\mathrm{CaCC}$ results in $\mathrm{Cl}^{-}$efflux from the cell, increasing mucus hydration. CaCC activation can be achieved by intracellular agonists or by increasing intracellular $\mathrm{Ca}^{2+}$ concentration. One of the pharmacological methods to increase intracellular $\mathrm{Ca}^{2+}$ concentration involves again using a $\mathrm{P}_{2} \mathrm{Y}_{2}$ agonist.

phase $1 / 2$ clinical trial [126], development has not advanced, except for a 2009 trial in xerostomia [127].

Another amiloride analogue, GS-9411, had greater solubility in HS, was 100 -fold more potent in vitro, maintained $75 \%$ more ENaC block following apical surface washes than amiloride, and had less permeability and increased metabolism in airway epithelium than amiloride, suggesting a better safety profile [128]. However, in phase 1 ascending-dose trials in healthy people $[129,130]$, GS9411 also blocked renal ENaCs, causing clinically significant hyperkalaemia [131]. Hence, the phase 1 trial in CF patients was withdrawn in 2009 [132]. 


\subsubsection{Pyrazinoyl Quaternary Amines}

Pyrazinoyl quaternary amines are structurally different from pyrazinoyl guanidine amiloride. Some show efficacy in vitro in human bronchial cells and in vivo in guinea pigs, having decreased cellular permeability and increased solubility (significant for administration methods, i.e. dry powder) [133]. 'Compound 12g' ( $\alpha$-branched quaternary amine) blocked $\mathrm{ENaC}$ and produced a guinea-pig tracheal potential difference 16 times greater than that induced by amiloride [134].

\subsubsection{Indirect $\mathrm{ENaC}$ Inhibitors}

5.1.2.1 Channel-Activating Protease Inhibitors

Channel-activating protease (CAP), prostasin, is a trypsin-like serine protease which cleaves $\mathrm{ENaC}$ channel subunits at specific sites, increasing ENaC activity [123].

Camostat is a low-molecular-weight CAP inhibitor which inhibits prostasin in vitro [135]. By inhibiting prostasin, camostat inhibits $\mathrm{ENaC}$ for $6 \mathrm{~h}$ after washing in vitro in human bronchial cells and increases MCC in vivo in sheep for $5 \mathrm{~h}$ after dosing [136]. In a phase 2 clinical trial in CF patients $(n=9)$ [137], camostat (nasal spray) reduced $\mathrm{Na}^{+}$efflux, causing a change in NPD of $+13.1 \mathrm{mV}$ from baseline, but 3 patients experienced serious adverse effects [138]. Concerns exist about camostat's specificity for certain CAPs and there is uncertainty regarding tolerance/safety with administration to lower airways by nebuliser [138].

\subsubsection{Small Peptide Inhibitors}

The small peptide RFSHRIPLLIF inhibits endogenous $\mathrm{ENaC}$ in vitro in human airway epithelia by blocking an ENaC $\gamma$-subunit domain [139].

\subsubsection{Purinergic Receptor Agonists}

$\mathrm{ENaC}$ is held open by $\mathrm{PIP}_{2}$ binding to the $\beta$-subunit of $\mathrm{ENaC}$ [140]. Agonising $\mathrm{P}_{2} \mathrm{Y}_{2}$ purinergic receptors decreases $\mathrm{PIP}_{2}$ levels by allowing hydrolysis of $\mathrm{PIP}_{2}$ to $\mathrm{IP}_{3}$ by phospholipase $\mathrm{C}$, thereby decreasing $\mathrm{ENaC}$ activation and increasing mucus hydration [140] (fig. 6). $\mathrm{P}_{2} \mathrm{Y}_{2}$ agonists also increase CFTR-independent $\mathrm{Cl}^{-}$efflux by activating $\mathrm{CaCC}$ by calcium-mediated signalling $[141,142]$ (fig. 6).

Previously, UTP (INS316) was used as a $\mathrm{P}_{2} \mathrm{Y}_{2}$ agonist because the endogenous agonist (ATP) caused adverse effects (bronchoconstriction and pulmonary vasodilation) [143]. Synthesis of diadenosine $5^{\prime}$-polyphosphates yielded denufosol [144], which inhibited $\mathrm{Na}^{+}$influx via $\mathrm{ENaC}$ [145], and increased $\mathrm{Cl}^{-}$secretion via CaCC activation (by increasing intracellular $\mathrm{Ca}^{2+}$ ) [145], resulting in mucus hydration and improved MCC. This caused prolonged $(8 \mathrm{~h})$ increased tracheal mucus velocity in vivo in sheep [146]. In a phase 3 trial [147] (TIGER-1; $\mathrm{n}=352)$, denufosol was well-tolerated and increased $\mathrm{FEV}_{1}$ from baseline to 0.048 litre (at week 24; placebo was 0.003 litre). Lung function change by denufosol, relative to placebo, was therefore small but significant (45 ml) [148].

In a second phase 3 trial [146] (TIGER-2; $\mathrm{n}=466$ ), denufosol caused a mean change in $\mathrm{FEV}_{1}$ from baseline to 0.040 litre (at week 48 ; placebo was 0.032 litre): lung function change by denufosol, relative to placebo, was now just $8 \mathrm{ml}$. The statistically insignificant difference may be attributed to less patient adherence in TIGER-2 than TIGER-1 or to the fact that denufosol fails to prevent longterm lung function decline (TIGER-2 lasted twice as long as TIGER-1) [149].

A phase 2 trial of denufosol [150] was initiated in 2010 in 2- to 4-year-old CF patients based on the concept that drugs with 'disease-modifying capability' be trialled in young children with low disease severity, where small short-term effects should be expected, but which have possible long-term efficacy [151].

\subsubsection{CaCC Agonists}

Several compounds activate $\mathrm{CaCC}$ (by increasing intracellular $\mathrm{Ca}^{2+}$, by binding near the $\mathrm{Ca}^{2+}$ binding site or allosterically - the latter two having increased target specificity, producing a sustained response, thereby increasing efficacy) [141]. Activation of CaCC results in $\mathrm{Cl}^{-}$efflux, which increases mucus hydration [152]. INO-4995 [1-O-octyl-2-O-butyryl-myo-inositol 3,4,5,6-tetrakisphosphate octakis(propionoxymethyl)ester] inhibits $\mathrm{ENaC}$ in vitro [153] and enhances $\mathrm{CaCC}$ action, showing increased $\mathrm{Cl}^{-}$efflux in human airway epithelial cells with enhanced effect in CF compared to WT $[154,155]$.

The bacterial polycyclic peptide duramycin (Moli1901/ lancovutide) activates CaCC in airway epithelium by causing $\mathrm{Ca}^{2+}$ influx via $\mathrm{Ca}^{2+}$-permeable pores and releases $\mathrm{Ca}^{2+}$ from intracellular stores [156]. However, in vitro in human colonic epithelial cells, duramycin disrupted cell membrane integrity by forming non-specific ion channels [157]. In a phase 2 trial $(n=24)$, nebulised duramycin was well-tolerated, had a long half-life, and did not enter the systemic circulation. $\mathrm{FEV}_{1}$ was increased (on day 26) by $8 \%$ from baseline, with the highest concentration of duramycin administered (2.5 mg/day) [158]. Another phase 2 (estimated $\mathrm{n}=160$ ) dosage-finding study was conducted in 2008 [159], the increased sample size showing promise. 


\section{Conclusions}

Properly hydrated mucus is a critical component of airway homeostasis. Failure to maintain adequate mucus hydration results in reduced MCC, which leads to mucus accumulation in the airways, causing impaired gas exchange and inflammation due to pathogen and proteolytic enzyme accumulation [11].

A 2013 meta-analysis of randomised clinical trials of CFTR gene replacement therapy concluded that transferring the correct CFTR gene via topical administration fails to produce clinical benefit [160]. Other ways to correct mutated-CFTR-induced abnormal ion concentration include correction of the processing of mutated CFTR using CFTR modulators, directly applying osmotic agents onto the ASL, or targeting other ion channels on the ciliated airway epithelial cell surface.
Of the therapies discussed herein, only 7\% HS and CFTR potentiator VX-770 (ivacaftor) are used clinically to hydrate mucus. Ivacaftor is currently only used with G551D-CFTR patients (clinical trials are underway testing its efficacy with other mutations). Therapies which may also succeed clinically are the osmolytic agent, mannitol, which shows more consistent efficacy than HS in clinical trials, the intracellular $\mathrm{Ca}^{2+}$-raising agent Moli1901/lancovutide, the PDE5 inhibitor sildefanil and the pharmacological chaperone VX-809 (lumacaftor), which is in clinical trials in combination with other CF drugs. Also, research into some chemical chaperones is relatively new, with SAHA, Ahal inhibitors and matrine showing positive results in vitro. Nevertheless, HS surprisingly remains the best treatment today, despite the CFTR gene mutation being first described in 1989 [3].

\section{References}

1 Rogers DF, Barnes PJ: Treatment of airway mucus hypersecretion. Ann Med 2006;38: 116-125.

2 Derichs N, Jin BJ, Song Y, et al: Hyperviscous airway periciliary and mucous liquid layers in cystic fibrosis measured by confocal fluorescence photobleaching. FASEB J 2011;25: 2325-2332.

3 Kerem B, Rommens JM, Buchanan JA, et al: Identification of the cystic fibrosis gene: genetic analysis. Science 1989;245:1073-1080.

4 Rowntree RK, Harris A: The phenotypic consequences of CFTR mutations. Ann Hum Genet 2003;67:471-485.

5 Rogan MP, Stoltz DA, Hornick DB: Cystic fibrosis transmembrane conductance regulator intracellular processing, trafficking, and opportunities for mutation-specific treatment. Chest 2011;139:1480-1490.

6 Osborne L, Santis G, Schwarz M, et al: Incidence and expression of the N1303K mutation of the cystic fibrosis (CFTR) gene. Hum Genet 1992;89:653-658.

7 Rich DP, Anderson MP, Gregory RJ, et al: Expression of cystic fibrosis transmembrane conductance regulator corrects defective chloride channel regulation in cystic fibrosis airway epithelial cells. Nature 1990;347:358-363.

8 Hwang TC, Sheppard DN: Gating of the $\mathrm{CFTR}^{-}$channel by ATP-driven nucleotidebinding domain dimerization. J Physiol 2009; 587:2151-2161.

9 Boucher RC: Cystic fibrosis: a disease of vulnerability to airway surface dehydration. Trends Mol Med 2007;13:231-240.

10 Boucher RC: Airway surface dehydration in cystic fibrosis: pathogenesis and therapy. Annu Rev Med 2007;58:157-170.
11 Boucher RC: New concepts of the pathogenesis of cystic fibrosis lung disease. Eur Respir J 2004;23:146-158.

12 Robinson M, Hemming AL, Regnis JA, et al: Effect of increasing doses of hypertonic saline on mucociliary clearance in patients with cystic fibrosis. Thorax 1997;52:900-903.

13 Boucher RC: Human airway ion transport. Part two. Am J Respir Crit Care Med 1994; 150:581-593.

14 Robinson M, Regnis JA, Bailey DL, et al: Effect of hypertonic saline, amiloride, and cough on mucociliary clearance in patients with cystic fibrosis. Am J Respir Crit Care Med 1996;153: 1503-1509.

15 Regnis JA, Robinson M, Bailey DL, et al: $\mathrm{Mu}$ cociliary clearance in patients with cystic fibrosis and in normal subjects. Am J Respir Crit Care Med 1994;150:66-71.

16 Button B, Boucher RC; University of North Carolina Virtual Lung Group: Role of mechanical stress in regulating airway surface hydration and mucus clearance rates. Respir Physiol Neurobiol 2008;163:189-201.

17 Rasgado-Flores H, Krishna Mandava V, Siman $\mathrm{H}$, et al: Effect of apical hyperosmotic sodium challenge and amiloride on sodium transport in human bronchial epithelial cells from cystic fibrosis donors. Am J Physiol Cell Physiol 2013;305:C1114-C1122.

18 King M, Dasgupta B, Tomkiewicz RP, et al: Rheology of cystic fibrosis sputum after in vitro treatment with hypertonic saline alone and in combination with recombinant human deoxyribonuclease I. Am J Respir Crit Care Med 1997;156:173-177.
19 Assouline G, Leibson V, Danon A: Stimulation of prostaglandin output from rat stomach by hypertonic solutions. Eur J Pharmacol 1977;44:271-273.

20 Haxel BR, Schafer D, Klimek L, et al: Prostaglandin E2 activates the ciliary beat frequency of cultured human nasal mucosa via the second messenger cyclic adenosine monophosphate. Eur Arch Otorhinolaryngol 2001;258: 230-235.

21 Donaldson SH, Bennett WD, Zeman KL, et al: Mucus clearance and lung function in cystic fibrosis with hypertonic saline. N Engl J Med 2006;354:241-250.

22 Elkins MR, Robinson M, Rose BR, et al: A controlled trial of long-term inhaled hypertonic saline in patients with cystic fibrosis. N Engl J Med 2006;354:229-240.

23 Rosenfeld M, Davis S, Brumback L, et al: Inhaled hypertonic saline in infants and toddlers with cystic fibrosis: short-term tolerability, adherence, and safety. Pediatr Pulmonol 2011;46:666-671.

24 Rosenfeld M, Ratjen F, Brumback L, et al: Inhaled hypertonic saline in infants and children younger than 6 years with cystic fibrosis: the ISIS randomized controlled trial. JAMA 2012;307:2269-2277.

25 Subbarao P, Stanojevic S, Brown M, et al: Lung clearance index as an outcome measure for clinical trials in young children with cystic fibrosis. A pilot study using inhaled hypertonic saline. Am J Respir Crit Care Med 2013;188: 456-460

26 Beydon N, Robinson PD: Early intervention for newborns screened for cystic fibrosis. Am J Respir Crit Care Med 2013;188:409-410.
Therapeutic Options for Hydrating Airway Mucus in CF
Pharmacology 2015;95:117-132 DOI: $10.1159 / 000377638$ 
27 Robinson M, Daviskas E, Eberl S, et al: The effect of inhaled mannitol on bronchial mucus clearance in cystic fibrosis patients: a pilot study. Eur Respir J 1999;14:678-685.

28 Daviskas E, Rubin BK: Effect of inhaled dry powder mannitol on mucus and its clearance. Expert Rev Respir Med 2013;7:65-75.

29 Tiddens HA, Donaldson SH, Rosenfeld M, et al: Cystic fibrosis lung disease starts in the small airways: can we treat it more effectively? Pediatr Pulmonol 2010;45:107-117.

30 Boucher RC: Evidence for airway surface dehydration as the initiating event in CF airway disease. J Intern Med 2007;261:5-16.

31 Daviskas E, Anderson SD, Eberl S, et al: Inhalation of dry powder mannitol improves clearance of mucus in patients with bronchiectasis. Am J Respir Crit Care Med 1999;159: 1843-1848.

32 Bilton D, Robinson P, Cooper P, et al: Inhaled dry powder mannitol in cystic fibrosis: an efficacy and safety study. Eur Respir J 2011;38: 1071-1080.

33 Aitken ML, Bellon G, De Boeck K, et al: Longterm inhaled dry powder mannitol in cystic fibrosis: an international randomized study. Am J Respir Crit Care Med 2012;185:645652.

34 Teper A, Jaques A, Charlton B: Inhaled mannitol in patients with cystic fibrosis: a randomised open-label dose response trial. J Cyst Fibros 2011;10:1-8

35 ClinicalTrials.gov: A service of the US National Institutes of Health. http://www.clinicaltrials.gov/ct2/show/NCT01883531.

36 Shoshani T, Augarten A, Gazit E, et al: Association of a nonsense mutation (W1282X), the most common mutation in the Ashkenazi Jewish cystic fibrosis patients in Israel, with presentation of severe disease. Am J Hum Genet 1992;50:222-228.

37 Dalemans W, Barbry P, Champigny G, et al: Altered chloride ion channel kinetics associated with the delta F508 cystic fibrosis mutation. Nature 1991;354:526-528.

38 Lewis HA, Buchanan SG, Burley SK, et al: Structure of nucleotide-binding domain 1 of the cystic fibrosis transmembrane conductance regulator. EMBO J 2004;23:282-293.

39 Haardt $M$, Benharouga $M$, Lechardeur D, et al: C-terminal truncations destabilize the cystic fibrosis transmembrane conductance regulator without impairing its biogenesis. A novel class of mutation. J Biol Chem 1999; 274:21873-21877.

40 Kerem E: Pharmacological induction of CFTR function in patients with cystic fibrosis: mutation-specific therapy. Pediatr Pulmonol 2005; $40: 183-196$.

41 Derichs N: Targeting a genetic defect: cystic fibrosis transmembrane conductance regulator modulators in cystic fibrosis. Eur Respir Rev 2013;22:58-65.

42 Howard M, Frizzell RA, Bedwell DM: Aminoglycoside antibiotics restore CFTR function by overcoming premature stop mutations. Nat Med 1996;2:467-469.
$43 \mathrm{Du}$ M, Jones JR, Lanier J, et al. Aminoglycoside suppression of a premature stop mutation in a Cftr-/- mouse carrying a human CFTR-G542X transgene. J Mol Med 2002;80: 595-604.

44 Smyth A, Lewis S, Bertenshaw C, et al: Casecontrol study of acute renal failure in patients with cystic fibrosis in the UK. Thorax 2008;63: 532-535.

45 Welch EM, Barton ER, Zhuo J, et al: PTC124 targets genetic disorders caused by nonsense mutations. Nature 2007;447:87-91.

46 Sermet-Gaudelus I, Boeck KD, Casimir GJ, et al: Ataluren (PTC124) induces cystic fibrosis transmembrane conductance regulator protein expression and activity in children with nonsense mutation cystic fibrosis. Am J Respir Crit Care Med 2010;182:12621272.

47 Kerem E, Hirawat S, Armoni S, et al: Effectiveness of PTC124 treatment of cystic fibrosis caused by nonsense mutations: a prospective phase II trial. Lancet 2008;372:719-727.

48 ClinicalTrials.gov: A service of the US National Institutes of Health. http://www.clinicaltrials.gov/ct2/show/NCT01140451.

49 Clunes MT, Boucher RC: Front-runners for pharmacotherapeutic correction of the airway ion transport defect in cystic fibrosis. Curr Opin Pharmacol 2008;8:292-299.

50 Rowe SM, Verkman AS: Cystic fibrosis transmembrane regulator correctors and potentiators. Cold Spring Harb Perspect Med 2013, DOI: 10.1101/cshperspect.a009761.

51 Chanoux RA, Rubenstein RC: Molecular chaperones as targets to circumvent the CFTR defect in cystic fibrosis. Front Pharmacol 2012;3:137.

52 Kopito RR: Biosynthesis and degradation of CFTR. Physiol Rev 1999;79:S167-S173.

53 Denning GM, Anderson MP, Amara JF, et al: Processing of mutant cystic fibrosis transmembrane conductance regulator is temperature-sensitive. Nature 1992;358:761-764.

54 Sato S, Ward CL, Krouse ME, et al: Glycerol reverses the misfolding phenotype of the most common cystic fibrosis mutation. J Biol Chem 1996;271:635-638.

55 Fischer H, Fukuda N, Barbry P, et al: Partial restoration of defective chloride conductance in DeltaF508 CF mice by trimethylamine oxide. Am J Physiol Lung Cell Mol Physiol 2001; 281:L52-L57.

56 Zhang XM, Wang XT, Yue H, et al: Organic solutes rescue the functional defect in delta F508 cystic fibrosis transmembrane conductance regulator. J Biol Chem 2003;278:5123251242.

57 Hutt D, Balch WE: Cell biology. The proteome in balance. Science 2010;329:766-767.

58 Nieddu E, Pollarolo B, Merello L, et al: F508del-CFTR rescue: a matter of cell stress response. Curr Pharm Des 2013;19:34763496.
59 Alberti S, Bohse K, Arndt V, et al: The cochaperone HspBP1 inhibits the CHIP ubiquitin ligase and stimulates the maturation of the cystic fibrosis transmembrane conductance regulator. Mol Biol Cell 2004;15:4003-4010.

60 Choo-Kang LR, Zeitlin PL: Induction of HSP70 promotes DeltaF508 CFTR trafficking. Am J Physiol Lung Cell Mol Physiol 2001; 281:L58-L68.

61 Imai J, Maruya M, Yashiroda H, et al: The molecular chaperone Hsp90 plays a role in the assembly and maintenance of the $26 \mathrm{~S}$ proteasome. EMBO J 2003;22:3557-3567.

62 Welch WJ, Brown CR: Influence of molecular and chemical chaperones on protein folding. Cell Stress Chaperones 1996;1:109-115.

63 ClinicalTrials.gov: A service of the US National Institutes of Health. http://www.clinicaltrials.gov/ct2/show/NCT00016744.

64 ClinicalTrials.gov: A service of the US National Institutes of Health. http://www.clinicaltrials.gov/ct2/show/NCT00590538.

65 Rubenstein RC, Zeitlin PL: A pilot clinical trial of oral sodium 4-phenylbutyrate (Buphenyl) in deltaF508-homozygous cystic fibrosis patients: partial restoration of nasal epithelial CFTR function. Am J Respir Crit Care Med 1998;157:484-490.

66 Rubenstein RC, Egan ME, Zeitlin PL: In vitro pharmacologic restoration of CFTR-mediated chloride transport with sodium 4-phenylbutyrate in cystic fibrosis epithelial cells containing delta F508-CFTR. J Clin Invest 1997; 100:2457-2465.

67 Rubenstein RC, Zeitlin PL: Sodium 4-phenylbutyrate downregulates Hsc70: implications for intracellular trafficking of DeltaF508CFTR. Am J Physiol Cell Physiol 2000; 278:C259-C267.

68 Egan ME, Glockner-Pagel J, Ambrose C, et al: Calcium-pump inhibitors induce functional surface expression of Delta F508-CFTR protein in cystic fibrosis epithelial cells. Nat Med 2002;8:485-492.

69 Egan ME, Pearson M, Weiner SA, et al: Curcumin, a major constituent of turmeric, corrects cystic fibrosis defects. Science 2004;304: 600-602.

70 Grubb BR, Gabriel SE, Mengos A, et al: SERCA pump inhibitors do not correct biosynthetic arrest of deltaF508 CFTR in cystic fibrosis. Am J Respir Cell Mol Biol 2006;34:355-363.

71 Song Y, Sonawane ND, Salinas D, et al: Evidence against the rescue of defective DeltaF508-CFTR cellular processing by curcumin in cell culture and mouse models. J Biol Chem 2004;279:40629-40633.

72 Dragomir A, Bjorstad J, Hjelte L, et al: Curcumin does not stimulate cAMP-mediated chloride transport in cystic fibrosis airway epithelial cells. Biochem Biophys Res Commun 2004;322:447-451.

73 Mall M, Kunzelmann K: Correction of the CF defect by curcumin: hypes and disappointments. BioEssays 2005;27:9-13. 
74 Harada K, Okiyoneda T, Hashimoto Y, et al: Curcumin enhances cystic fibrosis transmembrane regulator expression by downregulating calreticulin. Biochem Biophys Res Commun 2007;353:351-356.

75 Gelman JS, Sironi J, Berezniuk I, et al: Alterations of the intracellular peptidome in response to the proteasome inhibitor bortezomib. PLoS One 2013;8:e53263.

76 Trzcinska-Daneluti AM, Ly D, Huynh L, et al: High-content functional screen to identify proteins that correct F508del-CFTR function. Mol Cell Proteomics 2009;8:780-790.

77 Vij N, Fang S, Zeitlin PL: Selective inhibition of endoplasmic reticulum-associated degradation rescues DeltaF508-cystic fibrosis transmembrane regulator and suppresses interleukin-8 levels: therapeutic implications. J Biol Chem 2006;281:17369-17378.

78 Norez C, Noel S, Wilke M, et al: Rescue of functional delF508-CFTR channels in cystic fibrosis epithelial cells by the alpha-glucosidase inhibitor miglustat. FEBS Lett 2006;580: 2081-2086.

79 Lubamba B, Lebacq J, Lebecque P, et al: Airway delivery of low-dose miglustat normalizes nasal potential difference in F508del cystic fibrosis mice. Am J Respir Crit Care Med 2009;179:1022-1028.

80 Farinha CM, Amaral MD: Most F508delCFTR is targeted to degradation at an early folding checkpoint and independently of calnexin. Mol Cell Biol 2005;25:5242-5252.

81 Okiyoneda T, Niibori A, Harada K, et al: Role of calnexin in the ER quality control and productive folding of CFTR; differential effect of calnexin knockout on wild-type and DeltaF508 CFTR. Biochim Biophys Acta 2008; 1783:1585-1594.

82 ClinicalTrials.gov: A service of the US National Institutes of Health. http://www.clinicaltrials.gov/ct2/show/NCT00742092.

83 Leonard A, Lebecque P, Dingemanse J, et al: A randomized placebo-controlled trial of miglustat in cystic fibrosis based on nasal potential difference. J Cystic Fibrosis 2012;11:231-236.

84 Jenkins BA, Glenn LL: Miglustat effects on the basal nasal potential differences in cystic fibrosis. J Cyst Fibros 2013;12:88.

85 Leonard A, Lebecque P, Dingemanse J, et al: Miglustat effects on the basal nasal potential differences in cystic fibrosis. J Cyst Fibros 2013;12:89.

86 Hutt DM, Herman D, Rodrigues AP, et al: Reduced histone deacetylase 7 activity restores function to misfolded CFTR in cystic fibrosis. Nat Chem Biol 2010;6:25-33.

87 Wang X, Venable J, LaPointe P, et al: Hsp90 cochaperone Ahal downregulation rescues misfolding of CFTR in cystic fibrosis. Cell 2006;127:803-815.

88 Basile A, Pascale M, Franceschelli S, et al: Matrine modulates HSC70 levels and rescues DeltaF508-CFTR. J Cell Physiol 2012;227: 3317-3323.
89 Van Goor F, Straley KS, Cao D, et al: Rescue of DeltaF508-CFTR trafficking and gating in human cystic fibrosis airway primary cultures by small molecules. Am J Physiol Lung Cell Mol Physiol 2006;290:L1117-L1130.

90 Kim Chiaw P, Wellhauser L, Huan LJ, et al: A chemical corrector modifies the channel function of F508del-CFTR. Mol Pharmacol 2010;78:411-418.

91 Okiyoneda T, Veit G, Dekkers JF, et al: Mechanism-based corrector combination restores DeltaF508-CFTR folding and function. Nat Chem Biol 2013;9:444-454.

92 Loo TW, Bartlett MC, Clarke DM: Bithiazole correctors rescue CFTR mutants by two different mechanisms. Biochemistry 2013; 52:5161-5163.

93 Pedemonte N, Lukacs GL, Du K, et al: Smallmolecule correctors of defective DeltaF508CFTR cellular processing identified by highthroughput screening. J Clin Invest 2005; 115:2564-2571.

94 Ren HY, Grove DE, De La Rosa O, et al: VX809 corrects folding defects in cystic fibrosis transmembrane conductance regulator protein through action on membrane-spanning domain 1. Mol Biol Cell 2013;24:3016-3024.

95 Clancy JP, Rowe SM, Accurso FJ, et al: Results of a phase IIa study of VX-809, an investigational CFTR corrector compound, in subjects with cystic fibrosis homozygous for the F508del-CFTR mutation. Thorax 2012; 67:12-18.

96 ClinicalTrials.gov: A service of the US National Institutes of Health. http://www.clinicaltrials.gov/ct2/show/NCT01768663.

97 Pyle LC, Ehrhardt A, Mitchell LH, et al: Regulatory domain phosphorylation to distinguish the mechanistic basis underlying acute CFTR modulators. Am J Physiol Lung Cell Mol Physiol 2011;301:L587-L597.

98 Pasyk S, Li C, Ramjeesingh M, Bear CE: Direct interaction of a small-molecule modulator with G551D-CFTR, a cystic fibrosiscausing mutation associated with severe disease. Biochem J 2009;418:185-190.

$99 \mathrm{Yu} \mathrm{H}$, Burton B, Huang CJ, et al: Ivacaftor potentiation of multiple CFTR channels with gating mutations. J Cyst Fibros 2012;11: 237-245.

100 Jih KY, Hwang TC: VX-770 potentiates CFTR function by promoting decoupling between the gating cycle and ATP hydrolysis cycle. Proc Natl Acad Sci USA 2013;110: 4404-4409.

101 ClinicalTrials.gov: A service of the US National Institutes of Health. http://www.clinicaltrials.gov/ct2/show/NCT01784419.

102 ClinicalTrials.gov: A service of the US National Institutes of Health. http://www.clinicaltrials.gov/ct2/show/NCT01060566.
103 Boyle MP, Bell SC, Konstan MW, et al: A CFTR corrector (lumacaftor) and a CFTR potentiator (ivacaftor) for treatment of patients with cystic fibrosis who have a phe508del CFTR mutation: a phase 2 randomised controlled trial. Lancet Respir Med 2014;2:527-538.

104 Hwang TC, Wang F, Yang IC, et al: Genistein potentiates wild-type and delta F508CFTR channel activity. Am J Physiol 1997; 273:C988-C998.

105 Yu YC, Miki H, Nakamura Y, et al: Curcumin and genistein additively potentiate G551DCFTR. J Cyst Fibros 2011;10:243-252.

106 Ai T, Bompadre SG, Wang X, et al: Capsaicin potentiates wild-type and mutant cystic fibrosis transmembrane conductance regulator chloride-channel currents. Mol Pharmacol 2004;65:1415-1426.

107 Sohma Y, Yu YC, Hwang TC: Curcumin and genistein: the combined effects on diseaseassociated CFTR mutants and their clinical implications. Curr Pharm Des 2013;19: 3521-3528

108 Conger BT, Zhang S, Skinner D, et al: Comparison of cystic fibrosis transmembrane conductance regulator (CFTR) and ciliary beat frequency activation by the CFTR modulators Genistein, VRT-532, and UCCF-152 in primary sinonasal epithelial cultures. JAMA Otolaryngol Head Neck Surg 2013; 139:822-827.

109 Drumm ML, Wilkinson DJ, Smit LS, et al: Chloride conductance expressed by delta F508 and other mutant CFTRs in Xenopus oocytes. Science 1991;254:1797-1799.

110 Cheng SH, Gregory RJ, Marshall J, et al: Defective intracellular transport and processing of CFTR is the molecular basis of most cystic fibrosis. Cell 1990;63:827-834

111 Grubb B, Lazarowski E, Knowles M, et al: Isobutylmethylxanthine fails to stimulate chloride secretion in cystic fibrosis airway epithelia. Am J Respir Cell Mol Biol 1993;8:454-460.

112 Lubamba B, Lebacq J, Reychler G, et al: Inhaled phosphodiesterase type 5 inhibitors restore chloride transport in cystic fibrosis mice. Eur Respir J 2011;37:72-78.

113 Dhooghe B, Noel S, Bouzin C, et al: Correction of chloride transport and mislocalization of CFTR protein by vardenafil in the gastrointestinal tract of cystic fibrosis mice. PLoS One 2013;8:e77314.

114 Robert R, Carlile GW, Pavel C, et al: Structural analog of sildenafil identified as a novel corrector of the F508del-CFTR trafficking defect. Mol Pharmacol 2008;73:478-489.

115 Lubamba B, Lecourt H, Lebacq J, et al: Preclinical evidence that sildenafil and vardenafil activate chloride transport in cystic fibrosis. Am J Respir Crit Care Med 2008; 177 : 506-515.

116 Leier G, Bangel-Ruland N, Sobczak K, et al: Sildenafil acts as potentiator and corrector of CFTR but might be not suitable for the treatment of CF lung disease. Cell Physiol Biochem 2012;29:775-790.
Therapeutic Options for Hydrating Airway Mucus in CF
Pharmacology 2015;95:117-132 DOI: $10.1159 / 000377638$ 
117 ClinicalTrials.gov: A service of the US National Institutes of Health. http://www.clinicaltrials.gov/ct2/show/NCT01132482.

118 ClinicalTrials.gov: A service of the US National Institutes of Health. http://www.clinicaltrials.gov/ct2/show/NCT00659529.

119 Chen JH, Stoltz DA, Karp PH, et al: Loss of anion transport without increased sodium absorption characterizes newborn porcine cystic fibrosis airway epithelia. Cell 2010; 143:911-923.

120 Itani OA, Chen JH, Karp PH, et al: Human cystic fibrosis airway epithelia have reduced $\mathrm{Cl}^{-}$conductance but not increased $\mathrm{Na}^{+}$conductance. Proc Natl Acad Sci USA 2011;108: 10260-10265.

121 Kirk KL: Being positive: revisiting the elevated sodium permeability hypothesis in cystic fibrosis. J Physiol 2013;591:3675-3676.

122 Hollenhorst MI, Richter K, Fronius M: Ion transport by pulmonary epithelia. J Biomed Biotechnol 2011;2011:174306.

123 Althaus $\mathrm{M}$ : ENaC inhibitors and airway rehydration in cystic fibrosis: state of the art. Curr Mol Pharmacol 2013;6:3-12.

124 Hirsh AJ, Sabater JR, Zamurs A, et al: Evaluation of second generation amiloride analogs as therapy for cystic fibrosis lung disease. J Pharmacol Exp Ther 2004;311:929938.

125 Hirsh AJ, Zhang J, Zamurs A, et al: Pharmacological properties of $\mathrm{N}$-(3,5-diamino-6chloropyrazine-2-carbonyl)- $\mathrm{N}^{\prime}-4-[4-(2,3-$ dihydroxypropoxy)phenyl]butyl-guanidine methanesulfonate (552-02), a novel epithelial sodium channel blocker with potential clinical efficacy for cystic fibrosis lung disease. J Pharmacol Exp Ther 2008;325:77-88.

126 ClinicalTrials.gov: A service of the US National Institutes of Health. http://www.clinicaltrials.gov/ct2/show/study/NCT00274313.

127 ClinicalTrials.gov: A service of the US National Institutes of Health. http://www.clinicaltrials.gov/ct2/show/NCT00852839.

128 Hirsh AJ, St George J, Thelin W, et al: RGS 9411: a potential aerosol pharmacotherapy for CF. Am J Respir Crit Care Med 2009; 179:A1195.

129 ClinicalTrials.gov: A service of the US National Institutes of Health. http://www.clinicaltrials.gov/ct2/show/NCT00800579.

130 ClinicalTrials.gov: A service of the US National Institutes of Health. http://www.clinicaltrials.gov/ct2/show/NCT00999531.

131 O'Riordan TG, Donn KH, Hodsman P, et al: Acute hyperkalemia associated with inhalation of a potent $\mathrm{ENaC}$ antagonist: phase 1 trial of GS-9411. J Aerosol Med Pulm Drug Deliv 2014;27:200-208.

132 ClinicalTrials.gov: A service of the US National Institutes of Health. http://www.clinicaltrials.gov/ct2/show/NCT01025713.
133 Hunt T, Atherton-Watson HC, Axford J, et al: Discovery of a novel chemotype of potent human ENaC blockers using a bioisostere approach. Part 1: quaternary amines. Bioorg Med Chem Lett 2012;22:929-932.

134 Hunt T, Atherton-Watson HC, Collingwood SP, et al: Discovery of a novel chemotype of potent human $\mathrm{ENaC}$ blockers using a bioisostere approach. Part 2: alphabranched quaternary amines. Bioorg Med Chem Lett 2012;22:2877-2879.

135 Maekawa A, Kakizoe Y, Miyoshi T, et al: Camostat mesilate inhibits prostasin activity and reduces blood pressure and renal injury in salt-sensitive hypertension. J Hypertens 2009;27:181-189.

136 Coote K, Atherton-Watson HC, Sugar R, et al: Camostat attenuates airway epithelial sodium channel function in vivo through the inhibition of a channel-activating protease. J Pharmacol Exp Ther 2009;329:764-774.

137 ClinicalTrials.gov: A service of the US National Institutes of Health. http://www.clinicaltrials.gov/ct2/show/NCT00506792.

138 Rowe SM, Reeves G, Hathorne H, et al: Reduced sodium transport with nasal administration of the prostasin inhibitor camostat in subjects with cystic fibrosis. Chest 2013;144: 200-207.

139 Passero CJ, Carattino MD, Kashlan OB, et al: Defining an inhibitory domain in the gamma subunit of the epithelial sodium channel. Am J Physiol Renal Physiol 2010;299:F854F861.

140 Vallon V, Rieg T: Regulation of renal $\mathrm{NaCl}$ and water transport by the ATP/UTP/P2Y2 receptor system. Am J Physiol Renal Physiol 2011;301:F463-F475.

141 Namkung W, Yao Z, Finkbeiner WE, et al: Small-molecule activators of TMEM16A, a calcium-activated chloride channel, stimulate epithelial chloride secretion and intestinal contraction. FASEB J 2011;25:40484062.

142 Lazarowski ER, Boucher RC: Purinergic receptors in airway epithelia. Curr Opin Pharmacol 2009;9:262-267.

143 Olivier KN, Bennett WD, Hohneker KW, et al: Acute safety and effects on mucociliary clearance of aerosolized uridine $5^{\prime}$-triphosphate +/- amiloride in normal human adults. Am J Respir Crit Care Med 1996;154: 217-223.

144 Yerxa BR, Sabater JR, Davis CW, et al: Pharmacology of INS37217 [P(1)-(uridine $\left.5^{\prime}\right)$ $\mathrm{P}(4)$-( $2^{\prime}$-deoxycytidine $\left.5^{\prime}\right)$ tetraphosphate, tetrasodium salt], a next-generation P2Y(2) receptor agonist for the treatment of cystic fibrosis. J Pharmacol Exp Ther 2002;302: 871-880.
145 Monroe JS, Tomas N, Seiko FO, et al: Denufosol stimulates chloride transport, inhibits sodium absorption and restores airway surface liquid layer in primary airway epithelial cells from CF patients. Am J Respir Crit Care Med 2011;183:A6123.

146 ClinicalTrials.gov. A service of the US National Institutes of Health. http://www.clinicaltrials.gov/ct2/show/study/NCT00625612.

147 ClinicalTrials.gov. A service of the US National Institutes of Health. http://www.clinicaltrials.gov/ct2/show/study/NCT00357279.

148 Accurso FJ, Moss RB, Wilmott RW, et al: Denufosol tetrasodium in patients with cystic fibrosis and normal to mildly impaired lung function. Am J Respir Crit Care Med 2011;183:627-634.

149 Ratjen F, Durham T, Navratil T, et al: Long term effects of denufosol tetrasodium in patients with cystic fibrosis. J Cyst Fibros 2012; 11:539-549.

150 ClinicalTrials.gov: A service of the US National Institutes of Health. http://www.clinicaltrials.gov/ct2/show/NCT01181622.

151 Stick SM, Sly PD: Exciting new clinical trials in cystic fibrosis: infants need not apply. Am J Respir Crit Care Med 2011;183:1577-1578.

152 Melvin JE, Yule D, Shuttleworth T, et al Regulation of fluid and electrolyte secretion in salivary gland acinar cells. Annu Rev Physiol 2005;67:445-469.

153 Moody M, Pennington C, Schultz C, et al Inositol polyphosphate derivative inhibits $\mathrm{Na}^{+}$transport and improves fluid dynamics in cystic fibrosis airway epithelia. Am J Physiol Cell Physiol 2005;289:C512-C520.

154 Traynor-Kaplan AE, Moody M, Nur M, et al: INO-4995 therapeutic efficacy is enhanced with repeat dosing in cystic fibrosis knockout mice and human epithelia. Am J Respir Cell Mol Biol 2010;42:105-112.

155 Tian Y, Schreiber R, Wanitchakool P, et al Control of TMEM16A by INO-4995 and other inositolphosphates. Br J Pharmacol 2013;168:253-265.

156 Cloutier MM, Guernsey L, Sha'afi RI: Duramycin increases intracellular calcium in airway epithelium. Membr Biochem 1993;10: 107-118.

157 Sheth TR, Henderson RM, Hladky SB, et al: Ion channel formation by duramycin. Biochim Biophys Acta 1992;1107:179-185.

158 Grasemann H, Stehling F, Brunar H, et al: Inhalation of Moli1901 in patients with cystic fibrosis. Chest 2007;131:1461-1466.

159 ClinicalTrials.gov: A service of the US National Institutes of Health. http://www.clinicaltrials.gov/ct2/show/NCT00671736.

160 Lee TW, Southern KW: Topical cystic fibrosis transmembrane conductance regulator gene replacement for cystic fibrosis-related lung disease. Cochrane Database Syst Rev 2013;09:CD005599. 